\section{CONSIDERAÇÕES SOBRE O CARÁTER SOMBRIO NA MÚSICA}

revistamúsica | Vol. 18, n.2 |

pp. 66-8o | dez. 2018

\section{GANDHI MARTINEZ}

Universidade Estadual de Santa Catarina (UDESC) | gandhipiano@gmail.com

\section{ACÁCIO PIEDADE}

Universidade Estadual de Santa Catarina (UDESC) | acaciopiedade@gmail.com

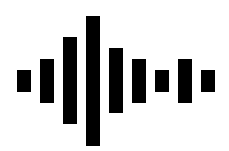

\section{CONSIDERATIONS ABOUT THE DARKNESS IN MUSIC}

\section{RESUMO}

Atualmente há uma forte presença do caráter sombrio nas artes, literatura e entretenimento. Este artigo busca investigar o sombrio como uma tópica musical através de um levantamento preliminar do campo do sombrio na música. Iniciamos discutindo questões como a luminosidade e suas associações com o medo, o diabólico e o grotesco. Após comentar o expressionismo no cinema e o movimento gótico dos anos 1980, apresentaremos um histórico do sombrio como uma tópica musical a partir de figuras de retórica do período barroco e tópicas posteriores como Ombra e Das Unheimliche. Na conclusão, sustentamos que o sombrio é uma tópica musical contemporânea, levando em conta toda essa trajetória histórica e sua intensificação pela arquitetura simbólica da indústria do entretenimento.

\section{PALAVRAS-CHAVE}

Sombrio. Tópica musical. Significado musical.

\section{ABSTRACT}

Currently there is a strong presence of the dark character in the Arts, Literature and Entertainment. By means of a preliminary survey of this field in music, this article aims to investigate darkness as a musical topic. We begin by discussing questions such as lack of luminosity and its associations with fear, the devilish, and the grotesque. After commenting on expressionism and on the Gothic movement of the 1980 s, we will present a history of the somber as musical topic departing from figures of musical rhetorics of the Baroque period and later topics such as Ombra and Das Unheimliche. In the conclusion, we will argue that darkness is a contemporary musical topic which includes its whole historical trajectory and its intensification by the symbolic architecture of the entertainment industry.

\section{KEYWORDS}

Darkness. Musical topics. Musical meaning. 


\title{
Considerações sobre o caráter sombrio na música
}

\author{
GANDHI MARTINEZ \\ Universidade do Estado de Santa Catarina (UDESC) | gandhipiano@gmail.com \\ ACÁCIO PIEDADE \\ Universidade do Estado de Santa Catarina (UDESC) | acaciopiedade@gmail.com
}

\begin{abstract}
Noite e música: O ouvido, o órgão do medo, pôde desenvolver-se tanto como se desenvolveu apenas na noite e na penumbra de cavernas e bosques sombrios, consoante $o$ modo de viver da época do medo, isto é, a mais longa época da humanidade: no claro, o ouvido não é tão necessário. Daí o caráter da música, uma arte da noite e da penumbra.
\end{abstract}

(Nietzsche, 2007, p. 173)

\section{Introdução}

O sombrio sempre esteve presente nas artes como um dos mais férteis campos de interesse e de temática, versando sobre o desconhecido, a aflição, o medo e a morte na experiência do ser humano, sendo aludido das mais diversas formas e com múltiplas intensidades. Neste artigo, pretendemos discutir alguns aspectos do sombrio na música e levantar algumas conexões possíveis em relação a essa ideia. Trata-se de um terreno complexo e por isso é importante de imediato pontuar claramente nossos objetivos, pois o campo é muito vasto e excede as questões musicais, abarcando necessariamente a filosofia e questões da história e da cultura, bem como da literatura e do Zeitgeist de diferentes épocas. Além disso, uma questão importante aqui é que o sombrio se apresenta como lugar comum fortemente investido pela indústria do entretenimento através de diversos meios, notadamente o cinema.

Atualmente há uma forte presença do sombrio, seja em formato estereotipado ou como referência tópica, em múltiplas obras de arte e produtos de entretenimento. Este é um fato relevante pois nos preocupamos com o sombrio enquanto tópica musical, ou seja, estrutura musical que porta uma significação de ordem ampla, histórica e cultural, como explicaremos adiante. Neste artigo não se pretende trazer um julgamento estético das formas mais ou menos elaboradas de se expressar o sombrio, e sim apenas promover uma investigação na esteira mesma do lugar comum - inevitável que é - a propósito de um levantamento preliminar do campo do sombrio na música através do comentário sobre alguns exemplos de repertórios específicos. Começaremos com comentários gerais sobre o sombrio envolvendo questões como a luminosidade-visibilidade e o medo, o diabólico, o grotesco, o sombrio nas Artes, entre outros 
aspectos. Comentaremos também o expressionismo no cinema e o movimento gótico dos anos 1980. Em seguida, apresentaremos o sombrio como uma tópica musical, a partir de figuras de retórica do período barroco e tópicas posteriores, já referidas na literatura musicológica, como Ombra e das Unheimliche. Neste ponto, tentaremos definir o sombrio como uma tópica contemporânea levando em conta toda essa trajetória histórica e sua acentuação pela arquitetura simbólica da indústria do entretenimento, sendo esta enfim a conclusão deste artigo.

\section{Uma investigação sobre o sombrio na História das Artes, na Estética e no Gótico}

O termo sombrio primariamente remete ao aspecto visual caracterizado pela penumbra, ou um ambiente com pouca luz. Essa ideia foi historicamente associada ao sentimento de medo devido à incerteza do conhecimento daquilo que a penumbra oculta. Quando se caminha por uma rua desconhecida, por exemplo, ao se deparar com um trecho pouco iluminado que impossibilita uma visão ampla da situação, a reação mais comum é a apreensão: os sentidos ficam aguçados e atentos, é uma reação instintiva de defesa e autopreservação, derivada do medo de ser atacado. A epígrafe acima, de Nietzsche, trata desse instinto que provavelmente acompanha o ser humano desde "a mais longa época da humanidade", quando este precisava viver na "penumbra de

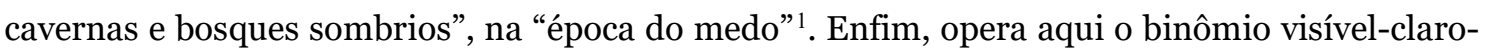
seguro/invisível-escuro-inseguro. Em muitas culturas, a percepção da noite se enquadra nesta dualidade. Ao tratar das representações em torno das sombras da noite no início da Idade Moderna, e dos perigos que lhe são inerentes, Delumeau (1990) afirma que "o desaparecimento da luz nos confina no isolamento, nos cerca de silêncio e, portanto, nos desassegura” (DELUMEAU, 1990, p. 99).

O conceito de medo é bastante evidente quando se trata de algo sombrio. Percebe-se que o medo de lugares escuros pode ter base em algo real, tangível, como a ameaça de algum ataque ou qualquer situação que possa resultar em algo trágico ou que ameace a vida (fruto do nosso instinto). Ou pode estar baseado em algo imaginado como sobrenatural, intangível, como a aparição de assombrações, fantasmas, demônios, e toda gama de coisas 'desconhecidas'. Essa visão está bastante presente nas religiosidades monoteístas ocidentais: onde o divino está há luz e há o bem, enquanto que no escuro habita o mal, o infernal demoníaco.

Tudo isso pode vir à tona quando depara-se com um lugar escuro, seja ele qual for. Numa visão mais ampla do sombrio na materialidade, pode-se dizer que a vida na Terra é totalmente dependente da entrada regular de energia que é fornecida por radiação do sol, portanto, o escuro, de uma forma profunda, pode ser encarado como a dificuldade para a vida, ou seja, sinônimo de morte - que por sua vez pode estar relacionada com a dualidade religiosa acima mencionada. Apesar da radiação não ter a ver diretamente com o sombrio enquanto modo de expressão, é

\footnotetext{
${ }^{1}$ A linguagem de Nietzsche pode ser lida como metafórica: a escuridão se refere à ausência da razão, que ilumina o mundo, ou seja, o abre para o conhecimento, conforme o pensamento iluminista. Ao mesmo tempo, a obra de Nietzsche de onde esta epígrafe foi retirada, Aurora, está tratando deste poder da razão na história da moralidade, e neste sentido o sombrio representaria a tradição, tacanha, e seus preconceitos morais.
} 
possível que esta característica esteja na base dos instintos, e pensando de modo amplo, pode estar ligada profundamente com nossas noções e relações com o sombrio. Talvez aí resida a nascente de um medo vasto e inconsciente do escuro.

A caverna é outro destacado lugar-símbolo da "era do medo". Segundo Banducci Jr. e Lobo (2012), "as cavernas sempre se constituíram uma referência para as sociedades humanas, seja como abrigo e espaço de realizações cerimoniais, em tempos remotos, seja como santuários ou centros de peregrinação" (BANDUCCI JUNIOR; LOBO, 2012, p. 586). Sabe-se que algumas cavernas possuem espaços de práticas mágicas e religiosas, em geral espaços mais profundos e escuros, e o imaginário cristão pode ter criado uma associação desta área ritual com ambientes ameaçadores e demoníacos. A ideia de caverna como local de medo foi fortemente alimentada a partir da Idade Média através do retrato construído por Dante Alighieri, na Divina Comédia, que associa o inferno a uma grande cratera existente no interior do globo terrestre (op. cit. p. 587). A caverna seria, portanto, ao mesmo tempo que um ambiente sombrio e assustador, uma porta de acesso a um mundo subterrâneo ainda mais terrível, escuro e asfixiante, habitado pelos demônios. Esta visão negativa das cavernas, no entanto, remonta à antiguidade: "na Bíblia, a palavra caverna aparece nove vezes. Em todas elas, o sentido dado ao termo é de esconderijo, covil, refúgio e, sobretudo, sepulcro" (op. cit. pp. 586-7).

Outra ideia que deriva daí é a de que o sombrio remete diretamente ao maligno e ao diabólico. Esta ideia perpassa a imaginação das pessoas de formas variadas e vem sendo traduzida pelas artes desde tempos remotos. É uma noção que está impregnada no imaginário ocidental principalmente devido à associação do escuro (trevas) com a ideia de inferno, tal como construída historicamente pelas religiões monoteístas, como o catolicismo. Esse lugar tenebroso, cheio de demônios, criaturas horripilantes e perversas que possuem as almas e as torturam, sob o comando

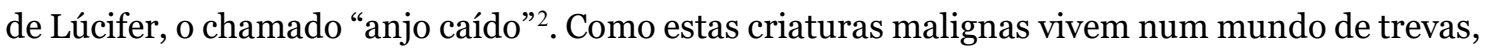
o elemento sombrio é associado e interpretado como sendo, ele mesmo, uma remissão direta à ruptura moral presente na ideia de anjo caído. Maldade e perversão são, desta forma, significados “colados" à ideia de sombrio, aparecendo como fossem características inerentes. Tudo o que é maligno passa então a fazer parte do imaginário do senso comum em relação ao sombrio, constituindo uma verdadeira "estética do Mal" (ECO, 2004, p. 337) que foi cultivada em diversas obras por muitos escritores e artistas, como Dante, Michelangelo, Rubens entre muitos outros. Em sua "estética do feio", Rosenkranz afirma:

O inferno não é apenas ético e religioso, é também inferno estético. Estamos mergulhados no mal e no pecado, mas também no feio. O terror do informe e da deformidade, da vulgaridade e da atrocidade nos circunda em inumeráveis figuras, desde os pigmeus até aquelas deformidades gigantescas cuja maldade infernal nos olha rangendo os dentes (ROSENKRANZ apud EcO, 2004, p. 135).

\footnotetext{
${ }^{2} \mathrm{Na}$ teologia protestante e católica, a ideia de anjo caído remete a uma decadência de origem sobretudo moral: trata-se de um anjo que, vivendo no paraíso, desenvolve cobiça por mais poder e, por isso mesmo, "cai" para o mundo das trevas. $\mathrm{Na}$ iconografia histórica e na indústria do entretenimento, as imagens do anjo caído apresentam: homem com grandes e negras asas de morcego; anjo sem halo e com as asas de penas negras; homem com a metade direita com asas de anjo e a metade esquerda com asas de demônio, entre muitas outras imagens.
} 
Se o mal foi associado ao escuro, a escuridão tem um papel importante como ambientação e espaço ritual no cristianismo. Um exemplo claro é a chamada tenebrae (trevas ou escuridão em latim), uma celebração cristã surgida no século XVI que ocorre nos três últimos dias da semana santa. A cerimônia distingue-se pelo candelabro de 15 velas, as quais vão sendo apagadas progressivamente ao final de cada salmo, sendo que a vela mais alta é apagada ao final da celebração, deixando a igreja em total escuridão (período conhecido como horas). Segundo Kendrick, "para observadores e participantes daquela época e de agora, esses serviços tiveram seu fascínio, devido à interação entre música e luz. [...] Com seus significados alegóricos variando das sombras da crucificação até as do pecado humano, tenebrae era uma extinção social da luz, e sua música era cada vez mais importante." 3 (KENDRICK, 2014, p. 7) Ainda segundo o autor, "tenebrae era um momento liminar, cuja performance estava aberta à intervenção demoníaca e divina. As exéquias de Cristo tornaram os participantes rituais suscetíveis a efeitos sobrenaturais em seus afetos" 4 (op. cit. p. 12). Acreditamos que esta cerimônia, importante na Igreja Católica até os dias de hoje, certamente ajudou a criar e difundir durante séculos certas noções de sombrio e suas conexões com a música.

Algumas características do sombrio são também encontradas naquilo que é chamado de grotesco. O distorcido, o monstruoso, o desordenado, o desproporcional são características do grotesco, mas também o diabólico, o atormentador, o infernal, o desarmônico, o tenebroso, o obsceno (KAYSER, 2003). O grotesco está muito presente nas obras de artistas plásticos como Velásquez, Goya, Bosch e Brueghel, onde aparecem retratadas pessoas com feições deformadas e maléficas mescladas a cenas inspiradas no inferno cristão, demônios, criaturas monstruosas e perversas em uma infinidade de situações envolvendo elementos sombrios. O grotesco, que perpassa diferentes períodos da arte é, para Bakhtin, um fenômeno em estado de transformação que se dá em diferentes sistemas dentro da cultura popular da Idade Média (cf. VARGAS, 2008, p. 10), avançando ao Renascimento, Romantismo e Modernidade, como no caso do surrealismo e do expressionismo. De fato, Bakhtin mostra como o grotesco se manifesta, a partir do corpo, desde as imagens cômicas da Idade Média até o espírito épico do carnaval, impondo na celebração da humanidade a incorporação de seu lado escuro 5 . Na literatura podemos encontrar o grotesco por exemplo em obras de Kafka, Dante, Mark Twain, Gogol e Poe, estes dois últimos constituindo ícones das chamadas literatura fantástica e da literatura gótica, respectivamente (cf. HOBBY, 2009).

Para Voss e Rowlandson (2013), a era moderna introduziu novos medos e desafios para a imaginação humana e o aparente desaparecimento das explicações religiosas redentoras resultou em uma exploração literária dos aspectos escuros da psique humana juntamente com as fobias sociais como parte de uma linguagem de horror: aqui entra a tradição literária chamada "gótica".

\footnotetext{
${ }_{3}^{3}$ For observers and participants then and now, these services have had their fascination, due to their interplay of music and light. [...] With its allegorical meanings ranging from the shadows of the Crucifixion to those of human sin, Tenebrae was a social extinguishing of light, the music of which was increasingly important (Tradução dos autores).

${ }_{4}^{4}$ Tenebrae was a liminal moment, one whose performance was open to both devilish and divine intervention. The exequies of Christ rendered ritual participants susceptible to supernatural effects on their affects (Tradução dos autores). 5 A incorporação do lado escuro da humanidade é uma forma de processá-lo na existência das massas humanas, multiformes, em constante transformação: "o grotesco, em outras palavras, sustenta em Bakhtin um tipo diferente de humanismo" (TiHANOV, 2012).
} 
Baseando-se em mitos antigos, o gótico surgiu em um momento particular na Europa e especialmente na Grã-Bretanha, como resposta a medos induzidos por mudanças socioeconômicas (op.cit., p. 144). Eco comenta que o romance gótico é "povoado de castelos e monastérios em decadência, subterrâneos inquietantes propícios a visões noturnas, delitos tenebrosos e fantasmas", levando a um tipo de erotismo mortuário, morbidez estética e um deleite pelo horror que caracteriza o decadentismo do final do século XIX (ECO, 2004, p. 288).

Assim, a feiura em si mesma também tem ligação direta com o sombrio e o grotesco. Como analisa Eco, o belo e o feio constituem um binômio estético, opondo o bonito, gracioso e agradável ao asqueroso, obsceno e repulsivo, esta dualidade estabelecendo uma longa cadeia de significados que se associa a cada um dos polos (Eco, 2007, p. 19). A literatura gótica e a literatura fantástica se alimentam frequentemente de elementos da feiura e do grotesco. Edgar Allan Poe, por exemplo, escreveu 25 contos publicados entre 1833 e 1845 como os Contos do Grotesco e do Arabesco $^{6}$, obra que teve grande circulação mundial e aceitação do público. Poe é considerado um dos mestres da literatura gótica que, como gênero literário, surgiu na Europa anglo-saxônica no século XVII e se consolidou nos Estados Unidos no século XIX (cf. BADDELEY, 2005). Talvez a literatura gótica tenha sido, antes do cinema, a grande responsável pela difusão global e construção do sombrio como lugar-comum na atualidade. Voltaremos a esse ponto.

Segundo Van Elferen (2012), o cinema, em sua fase inicial, já contribuiu para consolidar e difundir estes signos do gótico que remetem ao sombrio. O próprio cinema foi, para a visão de mundo da época, algo de espetacular e espectral: máquinas projetavam em enormes telas imagens em movimento, maiores do que na vida real, enquanto o público assistia com admiração, enclausurado em salas escuras. "Não é de surpreender que um grande número de filmes no início do cinema fossem adaptações de romances góticos populares do século XIX", afirma o autor (op. cit. p. 34).

O cinema expressionista alemão fez adaptações e releituras de romances góticos como Frankenstein (1818) de Mary Shelley, Drácula (1897) de Bram Stoker e O médico e o monstro (1885) de Robert Louis Stevenson. Segundo Fialho (2013), o expressionismo no cinema manifestou maciçamente o horror psicológico que predominava nos anos que antecederam a escalada nazista ao poder na Alemanha. Nesse momento, muitas obras artísticas estavam refletindo - e, pode-se dizer, tentando exumar e repelir - o espírito que nascia e que estava cercando e sufocando a Europa cada vez mais: algo certamente sombrio estava por vir no período da ascensão do Nazismo. O cinema expressionista é a vertente mais conhecida pelo grande público do movimento expressionista como um todo e, talvez por causa disso, tenha sido o meio mais efetivo da disseminação das concepções daquilo que hoje é entendido como sombrio. O filme Metrópolis (1926) de Fritz Lang, por exemplo, um dos mais importantes representantes desse gênero cinematográfico, traz a figura do robô no cinema como ícone de uma visão pessimista de futuro diante do crescimento desenfreado e manipulador do industrialismo. Metrópolis lança as

${ }^{6}$ No original intitulado Tales of the Grotesque and the Arabesque, e no Brasil publicado como Histórias Extraordinárias (1958). 
bases das distopias7 e ficções cientificas modernas, que inclui elementos como caos urbano, futuro sombrio, descontrole tecnológico e o contraste entre o belo e o perverso (Cf. HOLZMEISTER, 2010).

Da literatura fantástica e gótica, passando pelo cinema expressionista, o sombrio veio desembocar na subcultura gótica. Mas antes de tratar disso, é bom rever o termo "gótico", pois ele aponta tanto para a arte gótica e arquitetura medieval do leste europeu quanto para as artes visuais e literatura do período romântico, além deste conceito que nomeia uma subcultura jovem urbana do final do século XX. O termo se relaciona primeiramente com os godos, tribo germânica que invadiu a Europa Central e do Sul no século IV e criou um reino com os restos decadentes do Império Romano. Como resultado, a palavra "gótico" se tornou sinônimo de "bárbaro", o estrangeiro "estranho" e com hábitos de vândalos (nome de outra tribo da época), e o colapso do império romano assinalou o advento da Idade Média, que historicamente ficou conhecido como um longo período de trevas, com guerras e selvagerias (BADDELEY, 2005, p. 10).

O termo "gótico" foi usado por pensadores do período renascentista para descrever um tipo de arte e arquitetura representativa da cultura que, literal e simbolicamente, destruiu os restos do período românico. Esta nova estética foi criticada como sendo excessivamente pesada, sombria e melancólica, ainda que à época das construções, estas fossem consideradas luminosas.

Falando, por exemplo, da proporção, um filósofo medieval pensava nas dimensões e na forma de uma catedral gótica; enquanto um teórico renascentista pensava em um templo quinhentista, cujas partes eram reguladas pela seção áurea - e para os renascentistas pareciam bárbaras e, justamente "góticas", as proporções realizadas por aquelas catedrais (EcO, 2007, p. 10).

Finalmente, o termo "gótico" veio identificar uma subcultura ${ }^{8}$ jovem urbana do final do século XX que continha, e ainda contem, uma relação íntima com todos estes temas sombrios, salientando-se que "nem tudo que é obscuro e/ou macabro se insere no repertório e sensibilidade da subcultura gótica, mas o obscuro e o macabro são elementos essenciais” (KIPPER, 2008, pp. 46-7). Segundo Issitt, "os góticos são os mordomos de uma estética subterrânea que faz parte da cultura humana desde que os primeiros seres humanos viram algo bonito em meio a algo horrível" (IssiTT, 2011, p. 2). A subcultura gótica surge no início da década de 1980, influenciada por elementos de movimentos da contracultura como beatniks, hippies e punks dos anos 1970, e já nasce com um "desencantamento" ou uma desilusão em relação à cultura dominante (KIPPER, op . cit.). A subcultura gótica se difere da cultura "oficial" pois acolhe tanto os elementos oficiais

\footnotetext{
7 A distopia constitui um dos significantes do sombrio. Esta "anti-utopia”, ou utopia negativa, apresenta um futuro marcado pelo totalitarismo tecnológico e uma decadência moral e ecológica que resulta em cenários comumente sombrios. No imaginário distópico, a tecnologia geralmente constitui a ferramenta mais importante de controle social. Exemplos de romances distópicos são Admirável mundo novo (1932) de Aldous Huxley, 1984 (1949) de George Orwell, Fahrenheit 451 (1953) de Ray Bradbury, Laranja Mecânica (1962) de Anthony Burgess, Neuromancer (1984) de Wiliam Gibson. Quase todos foram adaptados para o cinema, que difundiu enormemente esta acepção do sombrio pela indústria do entretenimento.

${ }^{8}$ Segundo Cuche (2002), subculturas podem ser entendidas então como fragmentações de uma cultura de referência, delimitadas por classe, gênero, etnia, interesses e outros fatores. Nesses casos, a cultura global de referência não é negada, mas reestruturada, através de manipulações, filtragens e outros processos, de acordo com os interesses particulares dos grupos minoritários, contribuindo para a renovação e dinamização do sistema cultural como um todo. Uma subcultura pode ser definida como qualquer grupo cultural distinto dentro de uma cultura dominante. Uma contracultura, ao contrário, é um tipo de subcultura caracterizada pelo desenvolvimento de ideologias, estética ou outras crenças que estão em oposição direta à cultura dominante (ISSITT, 2011).
} 
quanto os aspectos obscuros e dramáticos que a sociedade dominante nega e desencoraja (op.cit., p. 70).

Ainda segundo Kipper, a subcultura gótica constitui um movimento jovem urbano nãocentralizado, ou seja, espalhado por países de todo o mundo. Além disso, "a subcultura gótica inclui produção musical, literária, cinematográfica, moda, comportamento, economia e trabalho (lojas, gravadoras, editoras, clubes) e entretenimento, etc." (KIPPER, 2008, p. 14) que revelam como o gótico "é uma estética, um ponto de vista, até mesmo um estilo de vida; sua tradição é um legado de subversão e sombras" (BADDELEY, 2005, p. 10).

O sombrio, portanto, é visto aqui como uma maneira de ver e interpretar o mundo, é encarado como princípio básico de um ideal estético e também como fonte de prazer. Eco finaliza seu livro História da Beleza (2004) afirmando que se um explorador do futuro quiser definir qual o ideal de beleza do século XX, terá um trabalho árduo pela frente, pois nesta era:

Os meios de comunicação repropõem uma iconografia oitocentista, o realismo fabulístico, a opulência junonal de Mae West e a graça anoréxica das últimas modelos; a Beleza negra de Naomi Campbell e a nórdica de Claudia Schiffer; a graça do sapateado tradicional de A Chorus Line e as arquiteturas futuristas e petrificantes de Blade Runner [...] O nosso explorador do futuro já não poderá distinguir o ideal estético difundido pelos mass media do século XX. Será obrigado a renderse diante da orgia de tolerância, de sincretismo total, de absoluto e irrefreável politeísmo da Beleza (Eco, 2004, p. 428).

A música foi a mola propulsora da subcultura gótica: nos anos 1980 surge, das cinzas da agonizante cena punk, alimentado pelo dandismo do glam rock da década de 1970, o rock gótico, que "sempre foi a mais coerente e difundida tradição gótica que já existiu" (BADDELEY, 2005, p. 14). Nesta música gótica, é muito importante "o uso de recursos que buscam causar efeitos normalmente adjetivados como escuro, profundo e sombrio" (KIPPER, 2008, p. 47). Esse objetivo estético é notável no uso da voz na música gótica: nas bandas consideradas góticas, os vocais masculinos tendem a ter "voz profunda e grave, ou entrecortada e sussurrante" enquanto os femininos variam de "fortes e mais agressivos (como no pós-punk) a etéricos [sic] ou sussurrantes" (op. cit. p. 47). Mesmo bandas góticas com vertentes mais dançáveis acabam mantendo a temática do obscuro e os vocais profundos com muito uso de reverber ${ }^{9}$, além das "letras sombrias e metafóricas" (op. cit.).

De fato, algumas características fundamentais da música gótica são: "efeitos sonoros, como reverb e distorção, melodias em regiões extremamente agudas ou extremamente graves, timbres sugestivos como flageolet (pequena flauta do período renascentista) ou ruído branco e harmonias em tonalidade menor" (VAN ElFEREN, 2012, p. 173). A música gótica nunca está distante de representações visuais do estilo e de seus interesses associados. Por exemplo, a parte gráfica dos álbuns e outras imagens relacionadas às bandas góticas apresentam aos fãs uma mensagem bastante clara a esse respeito: rostos brancos maquiados realçando a palidez, crânios, morcegos, caixões, vampiros, cruzes, símbolos antigos e outros objetos e imagens pinçados da iconografia

9 O reverber, com muita intensidade, pode remeter ao som no interior de uma caverna. E, como já foi visto, a caverna é um ambiente que traz muitos significados relacionados ao sombrio. 
histórica são parte integrante da imagem do gótico desde seu início. A música gótica busca aqueles ouvintes que estão "à procura do som sombrio" (ISSITT, 2011, p. 29).

Segundo Issitt, além do rock gótico tradicional, uma série de subgêneros musicais sombrios foram se associando à cultura gótica, incluindo "deathrock, medieval rock, EBM, darkwave, synthpop, electropop, gothabilly, cold wave, industrial metal, electro industrial, cyber metal, etc.” (op. cit. p. 10). É muito profícua essa ramificação do sombrio em diversos estilos relacionados. A cena de música eletrônica gótica, por exemplo, que abarca EBM (Eletronic Body Music), industrial, electro goth, darkwave, cyber-goth, future-pop, noise, entre outros subgêneros, surgiu na metade dos anos 1980 e traz referências tecnológicas e humanos interagindo com máquinas e robôs, bem como a ideia de futuro distópico no qual uma inteligência artificial dominará o mundo. Neste subtipo de música gótica há um amplo uso de sons eletrônicos e sintetizados, assim como de ruídos inspirados em sons industriais e de objetos mecânicos, o conceito visual sendo permeado por imagens de cenários urbanos futurísticos, onde convivem robôs, cyborgs (humanos com partes mecânicas e robôs com partes humanas - também presentes na estética cyberpunk ${ }^{10}$ ) e todo tipo de aparato ultra high tech.

\section{O sombrio como uma tópica musical}

Neste ponto, cremos já ter mostrado que o sombrio é um conceito bastante abrangente em termos históricos e simbólicos. Vamos agora tratar do sombrio na música, argumentando que se trata de um lugar comum, uma tópica musical, como tentaremos mostrar. De início, observe-se que o ouvinte comum, mesmo sem se ter consciência do que exatamente define o sombrio, sempre percebe quando algo invoca este caráter. E é por isso que tratamos dele como um lugar-comum de amplo espectro, dado que há um certo consenso do que seja algo sombrio, ao menos nas sociedades ocidentais que foram marcadas pela indústria do entretenimento, que estamos entendendo no sentido da indústria cultural, porém sem remeter diretamente ao conceito frankfurtiano (HORKHEIMER E ADORNO, 2002). Tentaremos tornar isto mais claro na parte final deste artigo.

Na música, os lugares-comuns se formam devido ao uso histórico e a persistência de certos elementos musicais que, durante um processo bastante complexo (cultural, psicológico, social), mantêm-se associados a certos significados. Uma teoria a respeito desse fenômeno do lugar comum na música e seus processos de significação que ficou conhecida como teoria das tópicas, tendo sido desenvolvida a partir de Ratner (1980) por diversos outros autores ${ }^{11}$. O que

10 "Se no início a imagem de um ser humano no qual vários órgãos haviam sido substituídos por aparelhos mecânicos ou eletrônicos, resultado de uma simbiose entre homem e máquina, ainda podia representar um pesadelo da ficção científica, com a estética cyberpunk o vaticínio realizou-se.” (ECO, 2007, p. 431).

${ }^{11}$ Segundo McKay (2007), a teoria das tópicas pode ser dividida em duas gerações de teóricos. A primeira é constituída por três textos influentes: o livro seminal de Leonard Ratner que estabeleceu a disciplina, Classic music: expression, form and style (1980); Rhythmic gesture in Mozart: Le nozze di Figaro and Don Giovanni (1983) de Wye Allanbrook; e Playing with signs: a semiotic interpretation of classical music (1991), de Kofi Agawu. A segunda geração alcança avanços significativos para a teoria das tópicas, principalmente por abordar algumas das suas lacunas semânticas, expressivas, semióticas e sócio históricas existentes nos trabalhos da primeira geração: aqui se encontram dois livros Robert Hatten, Musical meaning in Beethoven: markedness, correlation, and interpretation (1994) e Interpreting musical gestures, topics, and tropes: Mozart, Beethoven, Schubert (2004); e, de Raymond Monelle, Linguistics and semiotics in music 
pretendemos mostrar aqui é que entender o sombrio como uma tópica não é algo tão novo, visto que desde o período barroco algumas figuras já vinham apontando para este aspecto. Quando um/a compositor/a cria uma obra que é compreendida como portadora de um caráter sombrio, ele/a não está criando um novo sombrio mas simplesmente jogando com todas as noções préexistentes do que constitui o sombrio por meio de lugares-comuns estabelecidos devido ao uso histórico, repetido e transformado, sendo que a difusão global deste sombrio reconstituído pela indústria do entretenimento, notadamente o cinema, não deixa muitas dúvidas sobre a interpretação deste caráter. Portanto o sombrio sempre remete aos tantos lugares-comuns que constituem os sombrios anteriores, muitos dos quais mencionamos aqui.

Há algumas tópicas musicais que são identificadas como portadoras de um potencial de invocar o caráter sombrio, como: passus duriusculus, pianto, ombra e das Unheimliche ${ }^{12}$ (aqui traduzido por estranheza). Nos tratados do século XVII e XVIII podemos destacar algumas figuras que se relacionam à ideia de estranheza. De fato, a palavra duriusculus tem um significado similar: cobre a ideia da dureza nas harmonias e progressões melódicas, opondo-se a leveza. A cadentia duriuscula é uma cadência com material dissonante, o que provoca estranheza. Já o passus duriusculus é uma linha melódica ascendente ou descendente com alterações cromáticas. A catabasis ou descensus, figura sempre descendente, era usada para acompanhar imagens no texto referentes à descida e, neste caso, reporta às profundezas no sentido dos afetos negativos (ver BARTEL, 1997). Esse descenso foi alegoricamente associado à queda e ao inferno por alguns compositores (TARLING, 2004, p. 94) e também aos afetos mais deprimentes como humilhação e doença (CIVRA, 1991, p. 174). Entretanto a associação de afetos às figuras musicais no período barroco não era unívoca, pelo que se vê nos vários tratados da época, como é o caso das tonalidades, para as quais se atribuía éthoi muitas vezes bem distantes ${ }^{13}$. Para Monelle, o passus duriusculus é derivado da tópica pianto ${ }^{14}$ - que vem sendo usado pelos compositores desde o período barroco para criar momentos musicais de atmosfera triste e melancólica (MoNELLE, 2000, pp. 75-7). Segundo Williams, o uso da "quarta cromática15" era tão comum em fugas e fantasias que sua evasão dolorosa não era claramente universal, podendo também trazer

(1992) e The sense of music: semiotic essays (2000). Na América Latina, a teoria das tópicas tem sido adaptada e utilizada por um número crescente de autores, como Piedade (2003) e Plesch (2017).

${ }_{12}$ Freud propôs o termo unheimliche em texto publicado originalmente na revista Imago, em 1919. Portanto, unheimliche para Freud é algo "sinistro" ou "estranhamente familiar" e antônimo de heimlich, que é o "íntimo, secreto familiar, doméstico" (FREUD, 1986, pp. 237-269). Esse é considerado seu ensaio mais profundo no campo da estética. Nele, ressalta que nos extensos tratados sobre estética escritos até então somente havia espaço para sentimentos de natureza positiva, como o belo e o atraente em vez de estender-se também aos movimentos de repulsa e aflição. No entanto, segundo Eco, "a noção já circulava na cultura alemã há tempos e Freud havia encontrado num dicionário a definição de Schelling, que reza que unheimliche é tudo que deveria permanecer secreto, escondido e, no entanto, reaflora. Em 1906, Ernest Jentsch escreveu o seu Psychologie des Unheimlichens, definindo-o como alguma coisa de inusitado, que provoca 'incerteza intelectual' e diante da qual 'não se entende mais nada'. Freud discorria a respeito da etimologia do termo, examinando um campo semântico que compreende, em várias línguas, noções como estranho ou estrangeiro; uneasy, uncanny, ghastly, haunted, em inglês; inquiétant, sinistre, lugubre, mal à son aise, em francês; sospechoso, siniestro, em espanhol; demoníaco e horrendo, no árabe e no hebraico; e, por fim, desconfortável, que suscita trapidante horror, horripilante, que pode ser dito de um fantasma, da névoa, da noite, da rigidez de uma figura de pedra..." (Eco, 2007, p. 311) "Relaciona-se, sem dúvida, com a esfera do assustador, daquilo que gera angústia e horror, mas também é verdade que nem sempre o termo é usado num sentido claramente definido e, por isso, acaba por coincidir com tudo aquilo que, de uma maneira geral, provoca medo.” (FREUD apud ECO, 2007, p. 312)

${ }^{13}$ Por exemplo, a tonalidade de Mi maior, fatalmente triste para Mattheson, era doce e grandiosa para Rameau (ver quadro comparativo em (TARLING, 2004, p. 77).

14 Numa tradução literal: choro. O pianto se vincula e se confunde com o Lamento, tópica

${ }_{15}$ É como o autor nomeia esse movimento melódico descendente que abrange uma quarta justa através de cromatismo. 
significados de estranheza ${ }^{16}$, espanto, ameaça, magia." (WILLIAMS, 1997). De qualquer forma, percebe-se conotações negativas associadas ${ }^{17}$.

As figuras do período barroco e a teoria dos afetos que lhes foi associada constituem um sistema de significação instituído e largamente empregado na época e que, apesar das divergências, fundou as bases para uma sensibilidade individual e interiorizada, uma Empfindsamkeit, que vai conhecer grande expansão no século XIX, sendo que algumas das tópicas se solidificarão e se manterão estáveis, chegando aos nossos dias, quando a indústria do entretenimento vem a promover sua utilização e globalização através do cinema, como discutiremos adiante. Nessa região da sensibilidade individual interior, a subjetividade encontra outras imagens para os afetos. Por exemplo, tempestades são relacionadas alegoricamente com o tumulto interior, gerando, ainda no período clássico, a tópica que se chamou Sturm und Drang ${ }^{18}$, e o terror da escuridão e do mundo dos fantasmas vai ser cristalizado pela tópica Ombra, que discutiremos agora.

Carregada de elementos sombrios, a tópica ombra $^{19}$ foi usada no período clássico em certas cenas de ópera em que o fator sobrenatural estava em jogo. McClelland (2001) afirma que ombra é um termo que tem sido usado para designar certas cenas de ópera em que aparecem seres como demônios, bruxas ou fantasmas, em cenas que remontam aos primeiros dias da ópera e que foram comuns no século XVII na Itália e na França: "Óperas baseadas nas lendas de Orfeu, Lígia e Alcestis fornecem numerosos exemplos, que se estendem até o século XVIII" (MCCLELLAND, 2001, p. ii) ${ }^{20}$.

Segundo McClelland, as cenas de ombra tornaram-se populares por causa dos efeitos especiais usados no palco - efeitos de iluminação, cenários, fumaça, fogo, etc. - e por causa do uso crescente de efeitos musicais imponentes. No final do século XVIII, havia-se criado um elaborado conjunto de características sonoro-musicais associados à ombra, tais como: "trêmolos característicos, linhas cromáticas, acordes napolitanos e acordes de sétima diminuta" (KLEIN, 2005, p. 80). Além destas características citadas, McClelland acrescenta ainda: “andamento lento e constante, o uso de tonalidades menores, contornos melódicos descendentes, cromatismo e dissonância, ritmos pontuados e sincopados, pausas, tremolos, contrastes bruscos de dinâmica, progressões harmônicas inesperadas e instrumentação incomum." ${ }^{21}$ (MCCLELLAND, 2001, p.ii)

\footnotetext{
${ }^{16}$ Neste caso associado com das Unheimliche, como visto anteriormente.

${ }_{17}$ Dentre as obras que trazem o passus duriusculus e o pianto, referidas por Monelle (2000) e Williams (1997), estão Di lagrime indi (1585) de Marenzio; In Darkness Let Me Dwell (1610) de John Dowland; Dido and Aeneas (1688) de Purcell; o Kyrie da Missa em Si Menor (1733) e a Fuga em Láb BWV 886 de J. S. Bach; o Quinteto em Dó Menor, K. 406 (1787) de Mozart; Piangete valli abbandonate (1564) de Gioseppe Caimo; Tristão e Isolda (1865) de Wagner.

${ }_{18}$ Além de nomear o movimento literário alemão de meados de 1860, "Tempestade e Ímpeto" se manifesta como tópica musical no classicismo nos momentos de turbulência e ambiguidade tonal dada pela modulação, uma espécie de prenúncio do romantismo. McClelland comenta, entretanto, que o termo tempesta seria mais adequado para designar esta tópica, o que a leva, para alem de Mozart e Haydn, às primeiras óperas e ao pictorialismo musical das tempestades e devastações no teatro. Tempesta, argumenta, se tornaria assim uma contraparte de ombra, que discutiremos a seguir, o que configuraria dois estilos que se justaporiam nas cenas infernais. A base estética então seria não o Sturm und Drang mas o "sublime do terror" de Edmund Burke (ver MCCLELLAND, 2011).

19 Palavra italiana que significa sombra ou escuridão numa tradução literal para o português.

${ }^{20}$ Operas based on the legends of Orpheus, lphigenia and Alcestis provide numerous examples, extending well into the eighteenth century (Tradução dos autores).

${ }^{21}$ Slow sustained writing (reminiscent of church music), the use of flat keys (especially in the minor), angular melodic lines, chromaticism and dissonance, dotted rhythms and syncopation, pauses, tremolando effects, sudden dynamic contrasts, unexpected harmonic progressions and unusual instrumentation (Tradução dos autores).
} 
Músicas incorporando elementos da ombra gradualmente começaram a aparecer fora da ópera, como em oratórios e em música instrumental, mais frequentemente em introduções lentas de sinfonias. A ombra também pode ser encontrada na música sacra "nas áreas mais penitenciais da liturgia, e especialmente no Requiem, onde o suplicante é convidado a refletir sobre aquele que é, certamente, o maior evento sobrenatural de todos, o Julgamento Final" (Ibidem, p.vi). Ombra fornece uma fonte referencial para compositores do período clássico, como Mozart, que usou em óperas como: no oráculo em Idomeneo e na estátua em Don Giovanni. Na escrita instrumental, ombra também se apresenta muitas vezes, como na lenta introdução à Sinfonia Nr. 38 em Ré menor, Praga, K. 504. Ratner sugere que ombra no século XVIII invoca "moralidade e punição como meio de despertar temor e terror" 22 (RATnER, 1980, p. 24). Segundo Almeida e Neto, qualquer Requiem, em si mesmo, por suas associações com a morte, "ao inferno e ao Julgamento Final", já configura "um ambiente propício para passagens de ombra" (ALMEIDA; NETO, 2015, p. $5)^{23}$. Veremos agora o conceito de Unheimliche, uma decorrência do passus duriusculus e da catabasis.

A tópica das Unheimlich foi apresentada por Klein (2005), que a traduz do alemão para o inglês por uncanny: trata-se de qualquer coisa sobrenatural ou além do normal, trazendo apenas uma vaga relação com o sentido usual do adjetivo alemão unheimlich, que se refere ao esquisito, estranho, mas também ao sinistro e terrível. Klein afirma que "intimações da nossa mortalidade, intempestivas e fantasmagóricas, correm mais profundamente no contexto cultural alemão do unheimlich do que no contexto anglo-americano do uncanny" (KLEIN, 2005, p. 78) 24. Podemos trazer um aspecto psicológico dessa fantasmagoria da alteridade: segundo Masschelein, mudanças discursivas levam a trocas semânticas da estranheza freudiana com noções estéticas e filosóficas relacionadas com "o sublime, o fantástico e a alienação" (MASSCHELEIN, 2011, p. 5). Conceitos estéticos, como o belo, o grotesco, o gótico, podem ser relacionados com o estranho freudiano, e a maioria destes conceitos também aparece nas relações que Klein sugere sobre essa tópica da estranheza 25.

Cremos, portanto, que o sombrio como tópica musical já se encontra pré-configurado ao longo de séculos através do passus diuriusculus, catabasis, pianto, ombra e tópica da estranheza. Esta via de expressão musical do sombrio encontra forte consolidação no século XX com o cinema, o movimento gótico e a indústria do entretenimento, de modo que podemos afirmar que o

\footnotetext{
${ }^{22}$ Morality, and punishment as means of arousing awe and terror (Tradução dos autores).

23 Outras obras que trazem a tópica ombra encontradas analisadas no trabalho de McClelland (2001) são: Masonic Funeral Music (1785), Symphony No. 36 in C (1783), Symphony No. 38 in D (1786), Mass in C minor K139 (1768), Litaniae de Venerabili Altaris Sacramento (1762), Requiem (1791) de Mozart; 'He sent a thick darkness' Israel in Egypt (1738) e Admeto (1727) de Handel; Don Juan (1761) e Orfeo ed Euridice (1762) de Gluck; Seven Last Words (1785), Symphony No. 75 in D (1780) e Missa Cellensis (1766) de Haydn; La grotta di Trofonio (1785) de Salieri; Ode on the Spirits of Shakespeare (1776) de Linley; Cleofide (1731) de Hasse; Vologeso (1766) de Jommeli; Symphony in C minor (1783) de Kraus.

24 Intimations of our mortality, untimely and ghostly, run more deeply in the German cultural context of unheimlich than they perhaps do in the Anglo-American context of uncanny (Tradução dos autores).

25 Algumas das obras citadas ou analisadas por Klein (2005) e que trazem a tópica da estranheza são: Der Doppelgänger (1828) e Sonata in C minor, D 958, IV (1828) de Schubert; Piano Quartet in C minor, Op. 6o (1875) e Intermezzo in A major, Op. 118, No. 1 (1893) de Brahms; Tristan und Isolde (1865) de Wagner; Appassionata, Op. 57 (1805) de Beethoven; "Song of the Wood Dove" de Gurrelieder (1912) de Schoenberg; "Funeral March" Sonata, Op. 35 (1840) de Chopin.
} 
sombrio se tornou um lugar comum musical cada vez menos inconteste. Tentaremos agora ponderar sobre estes pontos e concluir este artigo.

\section{Comentários Finais}

Como se pode perceber, há um lugar comum na música que é entendido como sombrio, como a tópica ombra, a tópica do estranho, certas figuras da retórica musical do barroco. Nestes casos, há certos elementos sonoro-musicais de que se lança mão para criar tais atmosferas. Evidentemente, as técnicas empregadas variam ao longo da História e podemos ter certeza de que hoje estas tópicas não invocam os mesmos significados que antigamente, já que estes estão condicionados ao contexto histórico-cultural em que estão originalmente inseridos. Dentre os elementos sonoro-musicais do sombrio, conforme mencionados por Monelle (2000), McClelland, (2001), Klein, (2005) e Williams (1997), podemos destacar: região grave e extremamente grave; tonalidade menor ou ambiguidade tonal; andamento lento; linhas melódicas descendentes; cromatismo e dissonância; contrastes bruscos de dinâmica; progressões harmônicas inesperadas e modulações; instrumentação incomum; técnicas de orquestração como efeitos de tremolo, surdinas, harmônicos, sul ponticello, causando ruídos, rangidos e chiados; acordes de sétima diminuta e intervalo de terça ou sexta menor e trítono. Estes elementos têm um potencial de ajudar na criação do caráter sombrio em música, dependendo do cenário em que são empregados. A expressão do sombrio pode ser lograda quando estes parâmetros, combinados, agindo em conjunto, criam uma comunicabilidade e um discurso com uma intenção específica, sobretudo com apoio de imagens: "só o discurso é que estabeleceria a função, o nexo, o sentido dos eventos sucessivos" (COSTA, 2004, p. 83). O caráter imagético do sombrio musical também remonta a todo o histórico comentado neste artigo, desde as primeiras óperas, passando pelo cinema expressionista, mas é sobretudo com o movimento gótico e com a indústria do entretenimento que se vai acabar por difundir globalmente um caráter um pouco mais fixo e inequívoco do sombrio musical.

Atualmente, com a constante exposição e acesso a filmes, séries, imagens e músicas que denotam terror e escuridão, a tópica do sombrio se tornou um lugar comum tão desenhado e penetrante que não se pode evitar as associações que provoca em uma grande parte do ouvido musical ocidental ou ocidentalizado. Mesmo na música contemporânea de concerto, que por vezes busca se distanciar dos lugares comuns, a enunciação do sombrio depende de fatores que se fundamentam na tópica. Por exemplo, na obra Introduction aux Ténèbres, de Raphael Cendo (2009), que é estruturada no Apocalipse de São João e de onde o compositor extrai três canções em latim, o tratamento da voz, passando por manipulação eletrônica, traz à tona campos semânticos que se associam às trevas através da vocalidade do movimento gótico, com distorção e profundidade espacial. O demoníaco está especialmente evocado nesta obra, que emprega diversos dos parâmetros acima mencionados, sobretudo o registro grave. E, entretanto, trata-se de uma linguagem extremamente contemporânea, no sentido de inovadora e com certeza perturbadora. Isso mostra como o sombrio pode ser entendido como uma tópica no sentido 
amplo, que invade campos onde não é necessariamente ou conscientemente evocada, e que atravessa um longo período histórico, ainda que sempre se transformando, como ocorre com o motivo das trompas (MonelLE, 2006). A melancolia em algumas canções de John Dowland já evoca uma versão renascentista da tópica do sombrio (ROOLEY, 1983), assim como, na literatura do século XVIII, o sofrimento de Werther, que mescla suicídio-morte com beleza, espírito elevado e arte, configurou uma tópica literária que teve grande impacto na sua época. Este sombrio, ainda que transfigurado, se faz presente também nos filmes mencionados neste artigo, no rock gótico, e em toda a imagética do terror atual. O sombrio se mostra hoje uma tópica muito estável e com grande projeção histórica. Talvez este fato revele que sempre houve um sentimento de futuro sombrio para a humanidade, que se manifesta musicalmente de forma cada vez mais intensa. Lembramos aqui de Attali (1992), para quem a música tem este caráter profético, anunciando mudanças que estão por vir na sociedade. Talvez seja esse o caso.

\section{Referências}

AGAWU, V. Kofi. Playing with Signs: A Semiotic Interpretation of Classic Music. Princeton, N.J.: Princeton UP, 1991.

ALLANBROOK, Wye J. Rhythmic Gesture in Mozart: Le Nozze di Figaro and Don Giovanni. University of Chicago, 1983.

ALMEIDA, Ágata Y.; NETO, Dioníso M. Dies irae: tempesta e ombra em missas de réquiem luso-brasileiras. In: XXV Congresso da Associação Nacional de Pesquisa e Pós-Graduação em Música, Vitória, 2015.

ATTALI, Jacques. Noise: The Political Economy of Music. Minneapolis: University of Minnesota Press,1992.

BADELLEY, Gavin. Goth chic: um guia para a cultura dark. Rio de Janeiro: Rocco, 2005.

BANDUCCI JUNIOR, Álvaro; LOBO, Heros Augusto Santos. Turismo em cavernas e representações do subterrâneo, Pasos: Revista de Turismo y Patrimonio Cultural, vol. 10, no. 5, pp. 585-594, 2012.

BARTEL, Dietrich. Musica Poetica, Musical-Rhetorical figures in German Baroque Music. Lincoln: University of Nebraska Press, 1997.

COSTA, Rogério. Reflexões sobre a crise de comunicabilidade da música contemporânea: a música é linguagem? O que se deve comunicar a música? Revista Música Hodie, v. 4, n. 1, 2004.

CIVRA, Ferruccio. Musica Poética. Introduzione alla retorica musicale. Torino: Utete, 1991.

CUCHE, Denys. A noção de cultura nas Ciências Sociais. Bauru: EDUSC, 2002.

DELUMEAU, Jean. História do medo no Ocidente, 130o-18oo. São Paulo: Companhia das Letras, 1990.

ECO, Umberto. História da Beleza. Rio de Janeiro, Record, 2004.

História da Feiura. Rio de Janeiro, Record, 2007.

FIALHO, Marco A. L. Sombras que assombram: o expressionismo no cinema alemão. Rio de Janeiro: SESC, Dep. Nacional, 2013.

FREUD, Sigmund. Obras psicológicas completas. (Vol. XVII - 1917-1919). Rio de Janeiro: Imago, 1986.

HATTEN, Robert. Musical Meaning in Beethoven: Markedness, Correlation, and Interpretation. Bloomington: Indiana University Press, 1994.

. Interpreting Musical Gestures, Topics, and Tropes: Mozart, Beethoven, Schubert. Bloomington: Indiana University Press, 2004.

HOBBY, Blake (ed.) The Grotesque, Bloom's literary themes. Yale University: New York, 2009.

HOLZMEISTER, Silvana. O estranho na moda: a imagem nos anos 199o. São Paulo: Estação das Letras e Cores, 2010.

HORKHEIMER, Max; ADORNO, Theodor. A indústria cultural: o iluminismo como mistificação de massas. In: Luiz Costa Lima (Ed.) Teoria da cultura de massa. São Paulo: Paz e Terra, 2002, pp. 169-214. 
ISSITT, Micah L. Goths: A guide to An American Subculture. Santa Barbara: Greenwood, 2011.

KAYSER, Wolfgang. O Grotesco: configuração na pintura e na literatura. São Paulo: Perspectiva, 2003.

KENDRICK, Robert L. Singing Jeremiah: music and meaning in Holy Week. Bloomington: Indiana University Press, 2014.

KIPPER, H. A. A happy house in a black planet: Introdução à subcultura gótica. São Paulo: Editora do Autor, 2008.

KLEIN, Michael L. Intertextuality in Western Art Music. Bloomington: Indiana University Press: 2005.

MASSCHELEIN, Anneleen. The unconcept: the freudian in late-twentieth-century theory. Albany: State University of New York Press, 2011.

MCCLELLAND, Clive. Ombra Music in the Eighteenth Century: Context, Style and Signification. Tese de doutorado. The University of Leeds - School of Music, 2001.

MCKAY, Nicholas. On topics today. Zeitschrift der Gesellschaft für Musiktheorie, 4/1-2, pp. 159-183, 2007.

MONELLE, Raymond. Linguistics and Semiotics in Music. Chur, Switzerland: Harwood Academic Publishers, 1992.

The Sense of Music: Semiotic Essays. Princeton, NJ: Princeton University Press, 2000.

2006.

. The Musical Topic, Hunt, Military, and the Pastoral. Bloomington: Indiana University Press,

NIETZSCHE, Friedrich. Aurora. São Paulo: Ed. Escala, 2007.

PIEDADE, Acácio T. C. A teoria das tópicas e a musicalidade brasileira: reflexões sobre a retoricidade na música, El Oído pensante, v. 1, n. 1, 2013.

PLESCH, Melanie. Decentering Topic Theory. Musical Topics and Rhetorics of Identity in Latin American Art Music. Revista Portuguesa de Musicologia, 4/1, 2017, pp. 27-32.

RATNER, Leonard G. Classic Music: Expression, Form, and Style. New York: Schirmer Books, 1980.

ROOLEY, Anthony. New light on John Dowland's songs of darkness. Early Music, January, 1983, pp. 6-22.

TARLING, Judy. The Weapons of Rhetoric: a guide for musicians and audiences. Hertfordshire: Corda Music, 2004.

TIHANOV, Galin. A importância do grotesco. Bakhtiniana, Revista de Estudos do Discurso, v. 7, n. 2, São Paulo, Jul-Dez., 2012, pp. 166-180.

VAN ELFEREN, Isabella. Gothic Music: The Sounds of the Uncanny. Cardiff: University of Wales Press, 2012.

VARGAS, Antonio. Grotesco: Grotesque. Textos de Antonio Vargas e André Mesquita. Florianópolis, UDESC, 2008.

VOSS, Angela; ROWLANDSON, William. Daimonic Imagination: Uncanny Intelligence. Newcastle: Cambridge Scholars Publishing, 2013.

WILLIAMS, Peter. The Chromatic Fourth during Four Centuries of Music. Oxford: Clarendon Press, 1997. 